\title{
Laporan Kasus: Stage Closure untuk Gastroskisis
}

\author{
Tubagus Odih R Wahid ${ }^{1 *}$, Ari Alvaren², LofinaMutia Dewi², Putri Sari², Widya Cahya Purnama ${ }^{2}$
}

\begin{abstract}
Gastroschisis is a congenital defect of the anterior abdominal wall which is to the right of the umbilicus, gastric, small intestine and colon can be found outside the abdominal cavity. The incidence is 1: 2.500-10.000 births. The incidence of Gastroschisis in the world has increased in the last 30 years. In Indonesia, the incidence of Gastroschisis is not yet clear. The diagnosis is relatively easy by inspection and it is found that the contents of the abdomen are exposed outside the abdominal cavity. We reported a case of a baby patient aged six days when he was sent to Bagan Siapi Api Hospital and then performed the first stage operation, namely the installation of the bogota bag procedure, followed by gradual squist sac ligase treatment, after 18 days of treatment or at 37 days of age, devinitive surgery was performed close the abdominal wall defect.
\end{abstract}

Keywords: Gastroschisis, Squist Sac Ligation, stage closure

Gastroskisis adalah kelainan kongenital tidak terbentuknya dinding perut secara utuh. ${ }^{1,2}$ Gastroskisis terjadi karena pembentukan saluran cerna yang tidak normal saat proses embriologi yakni kegagalan perkembangan umbilical coelum berakibat adanya usus yang keluar dari dinding perut. $^{3}$ Insidensi gastroskisis dalam 3 dekade terakhir meningkat, sekitar 1:10.000 kelahiran. Usia ibu yang relative muda, bayi premature dan bayi dengan berat badan lahir rendah, perokok, pengguna narkoba, dan terpapar toksin kemungkinan beresiko terjadi gastroskisis saat hamil. Bayi laki-laki lebih sering menderita gastroskisis disbanding bayi perempuan. Angka kejadian gastroskisis di Indonesia belum jelas, namun Indonesia merupakan Negara dengan risiko tinggi

\footnotetext{
Penulis korespondensi: tubaguswahid@gmail.com ${ }^{1}$ KJFD Bedah Divisi Bedah Anak Fakultas Kedokteran Universitas Riau/ KSM Bedah RSUD Arifin Achmad Provinsi Riau. Pekanbaru, Riau, Indonesia ${ }^{2}$ Fakultas Kedokteran Universitas Riau, Pekanbaru, Riau, Indonesia
}

karena terdapat faktor risiko penyebab gastroskisis yaitu kehamilan pada usia muda, paritas tinggi dan kekurangan asupan gizi pada ibu hamil. ${ }^{4}$

\section{LAPORAN KASUS}

Seorang anak perempuan umur 47 hari dirawat di RSUD Arifin Achmad dengan diagnosis gastroskisis. Riwayat kelahiran secara sectio secaria di RSUD Bagan Siapi Api, dirawat sampai usia 5 hari. Kemudian dirujuk ke RSUD Arifin Achmad saat usia 6 hari (Gambar 1). Pada saat usia 9 hari dilakukan operasi pertama yaitu pemasangan bogotabag. Kemudian dilanjutkan dengan perawatan Squist Sac Ligation (Gambar2) yaitu perawatan dan tindakan secara bertahap melakukan gerakan seperti memeras kantong Bogota Bag dengan harapan secara bertahap isi gastroskisis masuk bertahap ke rongga abdomen. Perawatan ini dilakukan selama 18 hari. Setelah dievaluasi isi gastroskisis diprediksi dapat masuk ke rongga abdomen (Gambar3) maka saat usia pasien 37 hari dilakukan operasi definitive yakni penutupan 


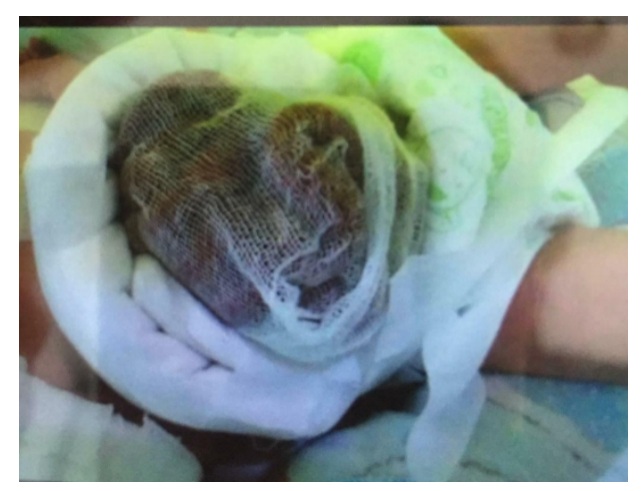

Gambar 1. Gambaran saat pasien pertama kali datang usia 6 hari, dengan usus terburai hanya ditutupi kasa lembab dan dibatasi kasa donat.

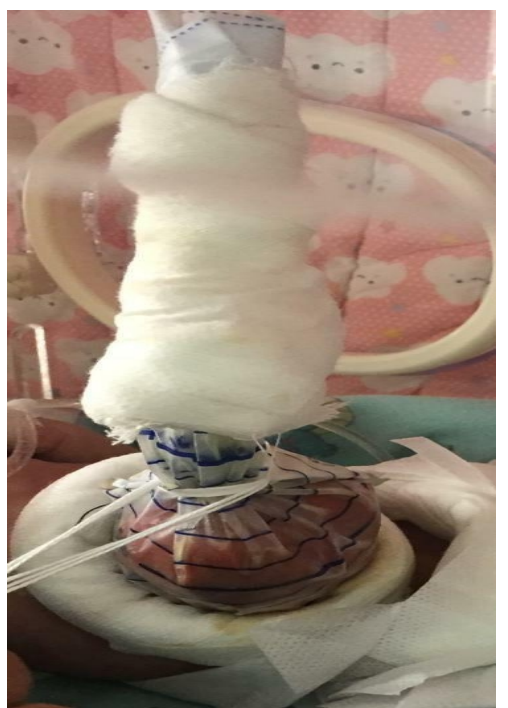

Gambar 2. Operasi pertama dengan pemasangan Bogota Bag dan dilanjutkan perawatan Squist Sac Ligationsecara bertahap.

defek gastroskisis pada dinding abdomen (Gambar 4). Pada saat operasi definitif, kondisi gastrointestinal terjadi adhesive dengan hepar dan vesika urinaria, kemudian dilakukan adhesiolisis hepar dan gastrointestinal dan vesika urinaria sampai bebas dan aliran gastrointestinal lancar sampai distal. Setelah memastikan kondisi perdarahan tidak ada dan aliran gastrointestinal lancar dengan pemisahan organ - organ visera lainnya selesai, maka dilanjutkan dengan penutupan defek dinding abdomen dengan menjaga jangan sampai terjadi compartement abdominal syndrome.

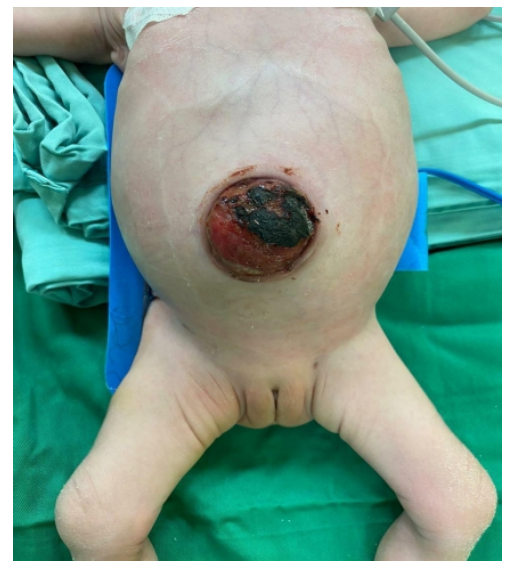

Gambar 3. Setelah perawatan 18 hari, dilakukan evaluasi klinis didapati isi gastroskisis telah diprediksi dapat dimasukan ke rongga abdomen.

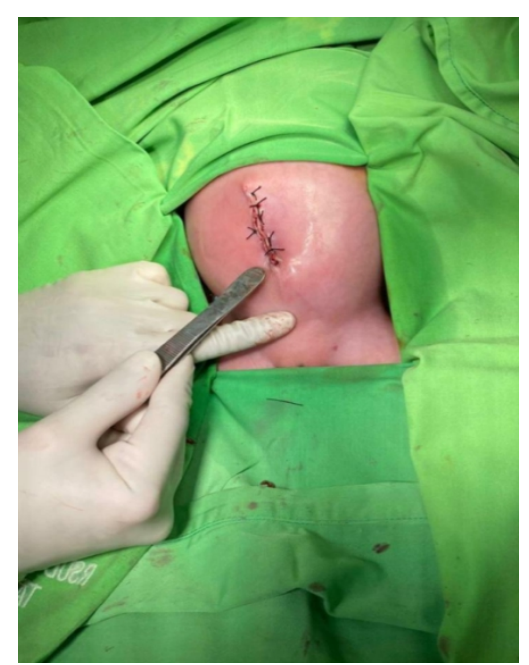

Gambar 4.Pasca operasi penutupan defek dinding abdomen

Rangkaian penanganan tersebut dalam satu pilihan yakni staged repair. Selanjutnya sampai laporan ini dituliskan pasien masih dalam perawatan pasca operasi definitive hari ke-8 dengan kondisi stabil dan diet telah dapat diberikan serta defekasi lancar.

\section{DISKUSI}

Gastroskisis merupakan kelainan bawaan yang tampilan klinisnya berat karena isi dari rongga abdomen terletak diluar tubuh pasien dan tidak ada penutupnya. Gastroskisis umumnya memiliki masalah respirasi terutama pada bayi premature yang dapat disertai dengan atresia intestinal dengan survival rate $40 \% .^{5}$ Penegakan diagnosis 
gastroskisis sebenarnya dapat ditegakkan sejak masa kehamilan, yakni dengan cara melakukan pemeriksaan USG pada usia kehamilan 10-12 minggu untuk mendeteksi defek pada dinding abdomen. USG pada usia kehamilan 20-27 minggu dapat mendeteksi adanya gastroskisis. ${ }^{6}$ Kadar alpha-fetoprotein dan acetylcholinesterase yang meningkat pada amnion menaikkan hingga 9 kali pada kejadian gastroskisis. ${ }^{6}$

\section{Penatalaksanaan}

Penanganan gastroskisis meliputi tatalaksana cairan, dekompresi, menghindari hipotermia. Pemberian antibiotik, biasanya digunakan kombinasi Ampisilin dan Gentamisin sesuai dosis terapi. Penatalaksanaan operatif gastroskisis yakni dapat repair primer atau bertahap. $^{6}$

\section{Penatalaksanaan Pembedahan}

Tindakan operasi gastroskisis bertujuan untuk memasukan kembali isi ke rongga perut dan meminimalkan resiko kerusakan visera abdomen karena compartment abdominal syndrome. Tindakan yang dipilih dapat berupa pemakaian silo (Bogota Bag), peras serial (Squist Sac Ligation) dan penundaan penutupan dinding abdomen baik primer atau bertahap. Inspeksi visera yang di luar meliputi obstruksi, perforasi, atau atresia wajib dikerjakan. Bila ada kelainan, diselesaikan sebelum pemasangan silo atau penutupan abdomen primer untuk menghindari terjadinya obstruksi usus. Hipomotilitas usus hampir didapatkan pada semua pasien Gastroskisis. ${ }^{2}$

\section{Primary Closure}

Penutupan primer gastroskisis dianjurkan disemua kasus. Cara ini merupakan pilihan agar isi gastroskisis memungkinkan dapat sempurna dimasukkan, tindakan ini dilaksanakan di kamar operasi. Dalam perkembangan terakhir dapat dilakukan di luar kamar operasi tanpa pembiusan umum. Sedangkan caranya bervariasi yakni menggunakan umbilikus sebagai allograft, alat mesh tidak diserap atau material bioprostetik. Setelah menutup lapisan fasia, flap kulit dapat untuk menutup dinding perut. Mayoritas ahli bedah akan membuang umbilikus saat dilakukan repair gastroskisis. Namun, pada beberapa kasus tetap dipertahankan. ${ }^{2,7}$

Compartment Abdominal Syndrome diidentifikasi melalui tekanan dalam kandung kemih dengan kateter, yakni diatas 10-15 $\mathrm{mmHg}$ yang berakibat menurunnya perfusi ginjal dan usus. Bila lebih dari $20 \mathrm{mmHg}$, berakibat gagal ginjal dan kekurangan oksigen usus. $^{2}$

Pada gastroskisis disertai atresia intestinal, penatalaksanaan reseksi dan anastomosis dapat dilakukan pada saat penutupan defek dinding abdomen. Jika tindakan anastomosis tidak memungkinkan, tindakan repair pada atresia intestinal dapat dilakukan 4-6 minggu kemudian setelah penutupan defek. Beberapa ahli bedah memilih untuk enterostomi pada kasus dengan atresia. ${ }^{7,8}$ Pada celah yang besar, banyak metode pilihan,seperti cutis graft terdiri dari dermis dan fasia rektus anterior. Flap otot, fasia dan kulit kanan kiri ke arah tengah untuk menutup fasia. Cara yang banyak dipakai sekarang menggunakan tissue exspander yang diletakkan di rongga abdomen untuk mereduksi disproporsi organ perut. ${ }^{2}$

\section{Staged Closure}

Penutupan bertahap menggunakan silastic/Bogota Bag yaitu silo. Cara ini memberikan trauma yang lebih ringan untuk pasien dan mencegah compartment abdominal syndrome. $^{8}$

Dua puluh tahun terakhir, pemakaian silo banyak digunakan secara bertahap, tujuan menghindari compartment abdominal syndrome dan iskemik visera dan menyebabkan ekstubasi menjadi lebih cepat.

Kantong penutup diperas (Squist Sac Ligation) setiap hari ke dalam ruang perut 
dimana silo akan memendek dengan ligasi yang berkelanjutan. Saat isi eviserasi telah tereduksi, penutupan definitif dikerjakan. Proses pemerasan umumnya antara 7 hingga 21 hari. ${ }^{2,9}$ Pada kasus ini dilakukan selama 18 hari atau lebih dari rata rata yang dilakukan yang pernah dipublikasikan.

\section{Outcome Jangka Panjang}

Hasil akhir jangka panjang dipengaruhi kondisi lainnya seperti adanya atresia usus yang dapat memperburuk prognosis, pemberian nutrisi parenteral lebih lama mengakibatkan hepar cholestasis dan penggunaan sentral berhubungan dengan sepsis. Prognosis tersebut berhubungan dengan peningkatan resiko kematian. Umumnya pasien gastroskisis dapat hidup normal. ${ }^{5,10}$

\section{DAFTAR PUSTAKA}

1. Correspondence. Postnatal intestinal ischemia in a patient with gastroschisis a sinister of home delivery and improper transportation. Journal of Pediatr Surg. 45;2010:2289-90.

2. Cassandra Kelleher, Jacob C. Langer. Congenital abdominal wall defects. J. Patrick Murphy George W. Holcomb. Ashcraft's Pedatric Surgery 5th edition. Philadelphia: Saunders Elselvier, 2010:62536.
3. Frolov P, Alali J, Klein MD. Clinical risk factors for gastroschisis and omphalocele in humans : a review of the literature. Pediatr Surg Int. 26;2010:1136- 46.

4. Setiawan WA. Prenatal diagnosis dan penatalaksanaan gastroskisis. Indonesian Journal of Obstetric and Gynecologyst Science.2019. 92-101.

5. Davis RP, Treadwell MC, Drongowski RA, et al. Risk stratification in gastroschisis: a prenatal evaluation or early postnatal factors predict outcome? Pediatr Surg Int. 25; 2009: 319-25.

6. Schwartz, Duane S. Duke and Marshall Z. Omphalocele and gastroschisis. Michael Hollwarts Prem Puri. Pediatric Surgery: Diagnosis and Management. Berlin Heidelberg : Springer-Verlag, 2010:161-70.

7. Riboh J, Abrajano CT, Garber K, et al. Outcomes of sutureless gastroschisis closure. Journal of Pediatr Surg. 44. 2009:1947-50.

8. Klein MD. Congenital defects of the abdominal wall. Pediatric Surgery.7th edition. Coran AG, Adzick NS,et al. Philadelphia. ElseiverSaunders,2012:973-84.

9. Houben $\mathrm{CH}$, Patel S. Gastroskisis Closure: a technique for improved cosmetic repair. Pediatr Surg Int. 24; 2008:1057-60.

10. Kassa AM, Lilja HE. Predictors of postnatal outcome in neonatus with gastroschisis. Journal of Pediatr Surg. 46; 2011:2108-14. 